\title{
Mesenteric carcinoid
}

\section{Ashlesha Satish Udare • Prabath Kumar Mondel • Abhijit Raut • Priya Hira}

Published online: 16 May 2012

(C) Indian Society of Gastroenterology 2012

A 65-year-old-man presented with intermittent periumbilical pain, nausea, diarrhea and bloating sensation for 6 months. Clinical examination was unremarkable apart from diffuse periumbilical tenderness. Blood count, liver and pancreatic enzyme levels were normal. Abdominal ultrasonography revealed focal well defined hypoechoic lesions in the liver and mesentery.

Multidetector CT showed an ill-defined spiculated mesenteric mass with fine central calcification and characteristic "stellate" appearance (Fig. 1). This appearance is due to mesenteric fibrosis and desmoplastic reaction [1]. A submucosal tumor in the ascending colon was also detected on CT. It was confirmed as carcinoid tumor on histopathology after surgical excision.

Carcinoid tumors are relatively rare neuroendocrine tumors comprising $2 \%$ of all gastrointestinal tumors [1]. Mesenteric carcinoid tumor is due to a metastasis from a carcinoid tumor of the small bowel beyond the ligament of Treitz [2]. Treatment options include somatostatin analogs, surgery and chemoembolization [1].

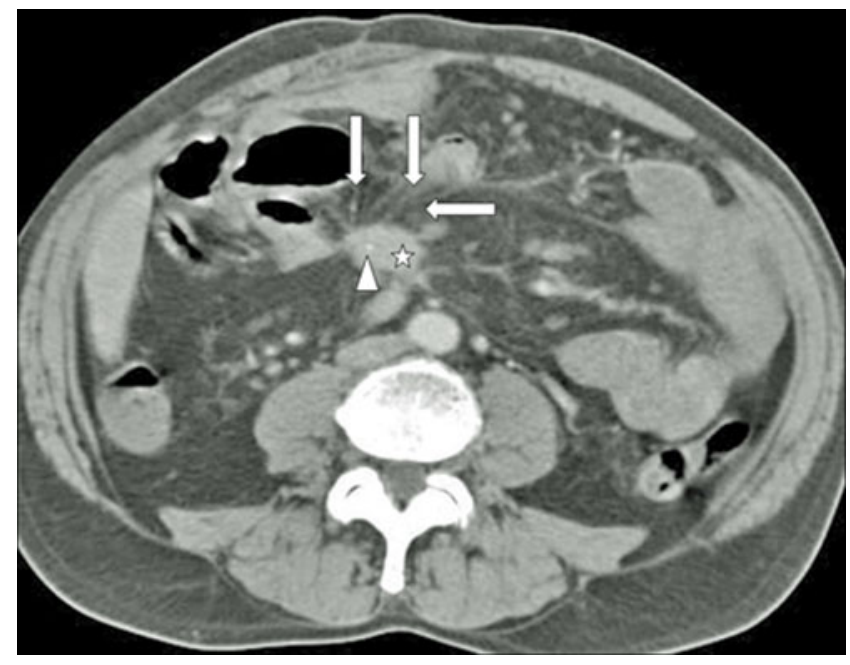

Fig. 1 Axial contrast enhanced MDCT image in the mid abdomen demonstrates mesenteric carcinoid $(\approx)$ fine central calcification (arrowhead) and characteristic "stellate" appearance (arrows) of the mesentery

A. S. Udare $(\bowtie) \cdot$ P. K. Mondel $\cdot$ P. Hira

Department of Radiology,

Seth G S Medical College and K E M Hospital,

Parel,

Mumbai 400 012, India

e-mail: ashleshaudare@gmail.com

\section{A. Raut}

Seven Hills Hospital,

Marol,

Mumbai 400 059, India

\section{References}

1. Horton KM, Kamel I, Hofmann L, Fishman EK. Carcinoid tumors of the small bowel: a multitechnique imaging approach. AJR Am J Roentgenol. 2004;182:559-67.

2. Pantongrag-Brown L, Buetow PC, Carr NJ, Lichtenstein JE, Buck JL. Calcification and fibrosis in mesenteric carcinoid tumor: CT findings and pathologic correlation. AJR Am J Roentgenol. 1995;164:387-91. 